\title{
Influence of physical setting on seagrass landscapes near Beaufort, North Carolina, USA
}

\author{
Mark S. Fonseca ${ }^{1, *}$, Susan S. Bell ${ }^{2}$ \\ ${ }^{1}$ National Marine Fisheries Service, NOAA, Southeast Fisheries Science Center, Beaufort Laboratory, 101 Pivers Island Road, \\ Beaufort, North Carolina 28516, USA \\ ${ }^{2}$ Department of Biology, University of South Florida, Tampa, Florida 33620, USA
}

\begin{abstract}
Field surveys were conducted in Core and Back Sounds, North Carolina, USA, to relate the physical setting of seagrass beds, as measured by a wave exposure index (REI), tidal current speed and water depth, to various measures of the sedimentary environment, spatial heterogeneity of seagrass distribution and measures of seagrass abundance. Seagrass beds in this area form patterns ranging from continuous to semi-continuous to widely dispersed, discrete patches across a gradient of increasing hydrodynamic activity. Tidal current speeds, exposure to waves and relative water depths revealed strong correlative evidence that physical processes influenced landscape-scale $(50 \times 50 \mathrm{~m}$ range with $1 \mathrm{~m}$ resolution) features of seagrass beds. Some habitat attributes, such as percent cover of seagrasses, seagrass bed perimeter to area ratio, sediment organic content and percent silt-clay. declined with increasing REI and current speed. Increased aggregation of these data was observed above and below the $50 \%$ seagrass cover value, and, supported by principle components analysis, signaled an abrupt transition of environmental setting correlated with this coverage level. The $50 \%$ cover value also occurred at current speeds of $-25 \mathrm{~cm} \mathrm{~s}^{-1}$. which should be near the initiation of motion current speed for local sand sediments, and an REI of $-3 \times 10^{6}$ This coverage is also near to the $59.28 \%$ coverage value, previously determined to be where landscape elements join and below which they tend to exist as discrete patches. We hypothesize that a rapid loss of seagrass habitat structural integrity may occur as the habitat fragments, and seagrass landscape elements become isolated, contributing to the observed transition and accompanying data aggregation above and below the $-50 \%$ coverage level. We discuss the interaction of physical setting, disturbance, landscape contiguity and growth response by these modular plants in the production of the observed landscape patterns across these hydrodynamic gradients.
\end{abstract}

KEY WORDS: Seagrass - Landsape Pattern - Waves C Current Water depth - Sediment - Disturbance

\section{INTRODUCTION}

Many studies, especially in freshwater systems, recognize the influence of hydrodynamic setting on vegetation structure and habitat function. For example, Keddy $(1982,1983)$ found that species composition and biomass of submerged aquatic vascular plants were highly correlated with wave exposure or, simply, fetch measurements. A similar result was reported by Coops et al. (1991), who concluded that wave regimes determined species composition of riparian vegetation. Likewise, Duarte \& Kalff (1990) recorded a negative relationship between physical (wave exposure, bottom

•E-mail: mark.fonseca@noaa.gov slope) and biotic (e.g plant biomass) parameters in some temperate lakes. Population level responses, such as sexual reproduction, have also been reported to be higher in wave-exposed areas (Duarte \& Kalff 1990). These freshwater studies reaffirm a link between physical processes and aquatic plant growth and persistence.

In shallow water marine settings, seagrasses often occur as large, semi-continuous beds. The patterns of seagrass coverage, however, vary markedly, from that of continuous cover over hundreds of meters to patches that are meters to tens of meters across the largest dimension. In the seagrass ecosystem, the association among these bed patterns or landscapes (see Robbins \& Bell 1994) and physical setting has been suspected (Patriquin 1975, Fonseca et al. 1983, Kirkman \& Kuo 
1990, Fonseca 1996a) but rarely studied. Interestingly, despite the relative paucity of studies quantitatively linking seagrass bed patterns with water motion, the links between seagrass bed pattern and water motion have been acknowledged in numerous studies investigating faunal associations in seagrasses. O'Gower \& Wacasey (1967) recognized the role of hydrodynamics in structuring seagrass beds and stratified their faunal sampling based upon current speed regimes. Both Orth (1977) and Pihl (1986) recorded differences in faunal attributes (biomass, secondary production, and species composition) within seagrass beds experiencing different wave exposures and/or current regimes. Bell et al. (1994) found that fish species composition and their feeding strategies had strongest similarity within a given hydrodynamic regime. Other studies also reported variation in faunal abundance as seagrass coverage changed (e.g. Irlandi et al. 1995, Murphey \& Fonseca 1995). The aforementioned work strongly suggests that hydrodynamic (flow) regimes may be coupled not only to spatial patterns of vegetation but also indirectly with faunal abundance, composition and trophic interactions.

Within seagrass beds there are a number of possible mechanisms by which flow regime and the resultant spatial patterns exhibited by vegetation are related. Spatial patterns of seagrass distribution under gradients of flow regimes may arise from physical disturbance events that act to arrest seagrass bed development in a chronically patchy pattern (Fonseca et al. 1983, Kirkman \& Kuo 1990, Fonseca 1996b). Moreover, some of the variation of coverage that exists within seagrass landscapes may be a result of differences in biological disturbance processes (bioturbation) that have been shown to increase and maintain spatial heterogeneity of seagrass beds (Suchanek 1983, Philippart 1994, Valentine et al. 1994, Townsend \& Fonseca 1998). While it is almost certain that disturbance plays a significant role in affecting seagrass bed pattern (Patriquin 1975. Fonseca et al. 1983), architectural responses by the plants themselves may also contribute to these patterns. As observed for clonal terrestrial plants (Lovett-Doust 1981, Sutherland \& Stillman 1988), seagrasses may respond to different environmental settings by altering growth architecture. Moreover, hydrodynamically induced changes in plant morphology and/or clonal architecture may influence plant resistance to being dislodged or damaged or rhizome branching frequency and direction, any of which could affect the geometry of the seagrass bed. In aquatic environments, the effect of flow regime on individual plant morphology is well recognized (e.g Charters et al. 1969, Koehl 1986. Koehl \& Alberte 1988, Armstrong 1989, Chambers et al. 1991, Levin \& Mathieson 1991). although the relationship between local (ramet) mor- phological variation of seagrass in response to hydrodynamic setting and that of larger scale spatial patterns remains unknown.

In this study, we focus mainly upon the relationships between physical setting and spatial pattirns of seagrass beds observed at the horizontal extent of $2500 \mathrm{~m}^{2}$. We conducted field surveys to relate various measures of the seagrass bed sedimentary environment, spatial heterogeneity of seagrass distribution and measures of seagrass abundance to the physical setting of seagrass beds as measured by exposure to wind waves, tidal current speed and relative water depth. These 3 measures of physical setting were chosen because waves and tidal currents are sources of mechanical disturbance and are both mediated by water depth through several physical laws. Our approach was to develop a quantitative relationship between the seagrass beds and their physical setting that could be later tested for its geographic applicability.

\section{METHODS}

Study site selection and seagrass coverage. Seagrass coverage data were determined by mapping 18 study sites in Core and Back Sounds, Carteret County, North Carolina, USA (latitude $34^{\circ} 40^{\prime}$ to $34^{\circ} 50^{\prime} \mathrm{N}$, longitude $76^{\circ} 20^{\prime}$ to $76^{\circ} 40^{\prime} \mathrm{W}$ ). Seagrass beds along this portion of the North Carolina coast cover $\sim 7000$ hectares in a nearly continuous, $\sim 1 \mathrm{~km}$ swath behind the extensive barrier island system (Ferguson et al. 1991). Within this broad landscape, sites were chosen based on examination of 1:24000 scale aerial photographs and ground truthing to represent a wide range of seagrass coverage (post facto surveys revealed a range of 13 to $100 \%$ ). Sites were occupied by a mixture of 2 dominant species, Zostera marina (eelgrass) and Halodule wrightii (shoalgrass). Carteret County represents the southernmost area with large overlapping acreage of these 2 species on the east coast of the United States. Their occurrence here is marked by different seasonal peaks of abundance (Thayer et al. 1984). Because these species often intermingle at the sub-meter scale in this area, no distinction among species was made during mapping.

After selecting the general location of the study site from the aerial photographs, the actual position and orientation of the $50 \times 50 \mathrm{~m}$ areas were chosen haphazardly within portions of the seagrass landscape that appeared to have a consistent pattern of cover for at least $100 \mathrm{~m}$ beyond the boundaries of the study site. Mapping was conducted in May and November 1991 and May-June and November 1992. Each site was delineated by installing permanent markers at the cor- 
ners of a $50 \times 50 \mathrm{~m}$ area. A $1 \mathrm{~m}^{2}$ area centered on the intersection of meter square grids on the site was surveyed for presence/absence of seagrass by direct observation while systematically moving a pre-marked ( $1 \mathrm{~m}$ increment) lead line across the site. The lead line was held perpendicular to tape measures laid along parallel sides of the site, allowing us to subsequently revisit each of the 2500 grid points. An inverted, Tshaped piece of PVC pipe $(2 \mathrm{~m}$ across the ' $\mathrm{T}$ ', with the handle being the stem of the ' $T$ ') was used to locate 3 parallel transects spaced $1 \mathrm{~m}$ apart. Because of waves and tidal currents, our lead line was sometimes displaced laterally although this displacement was observed to be less than $1 \mathrm{~m}$. Water depth was recorded to the nearest decimeter at every grid point on every third transect, beginning November 1991. Water depth was corrected for tidal change during the course of each survey. The spatially explicit data produced from site surveys on seagrass presence/absence and water depth were analyzed for percent cover using SAS ${ }^{\mathrm{TM}}$ (1989).

Seagrass biomass and density. Three plant cores of 15 or $25 \mathrm{~cm}$ diameter were taken from each of $3 \mathrm{ran}$ domly selected, $1 \mathrm{~m}^{2}$ locations which had seagrass cover, in each of the 18 study plots, with the smaller cores used in the higher shoot density, Halodule wrightii-dominated beds. The 4 survey times (May and November 1991, May-June and November 1992) were chosen to roughly coincide with the peak biomass of the 2 dominant seagrass species. Samples were taken to $-20 \mathrm{~cm}$ sediment depth to include root and rhizomes as well as above ground plant material. After washing plants free of sediment, they were placed in zip-lock bags on ice in the field and later frozen. For processing, seagrass shoots were thawed and separated from the rhizome. All rhizome and root material was soaked in a 5 to $10 \%$ phosphoric acid bath for $10 \mathrm{~min}$ and then rinsed with fresh water. All dead rhizome material (blackened and soft rhizome) was removed. Dry weight ( $\mathrm{dw}$ ) of the live rhizome material and attached roots was recorded after drying to a constant weight at $80^{\circ} \mathrm{C}$.

Shoots were enumerated for all seagrass species within each core. The number of flowering shoots was recorded for Zostera marina and the percent flowering computed; no Halodule wrightii flowering shoots were detected. Ten shoots of each species were randomly selected for measurement of morphology and biomass. If less than 10 were available, all were used. The leaves were prepared for biomass estimates as rhizomes were. The average dw per shoot was computed and multiplied by the number of shoots on $\mathrm{a}^{2}$ basis to obtain unit area biomass values by seagrass species. Because plant dimensions and biomass were highly correlated (authors' unpubl. data) only biomass data are presented here. All plant parameters are grand means laveraged within each $1 \mathrm{~m}^{2}$ sampling location then averaged among the 3 locations at each site $(n=$ 3) per sampling time]. The relative dominance of seagrass Halodule wrightii versus Zostera marina was computed as a ratio of shoot numbers $\mathrm{m}^{-2}$ by physical setting to determine if species distribution was correlated with environmental conditions associated with physical setting

Sediment sampling. Sediment cores $(3 \mathrm{~cm}$ diameter) were taken in conjunction with plant cores. One core was taken from each of the 3 random $1 \mathrm{~m}^{2}$ locations within a site $(n=3)$ in each sampling period, but prior to plant coring. The top $3 \mathrm{~cm}$ of the cores were extracted, any plant or animal fragments recognizable by eye as to their parent source were removed and the remainder analyzed for particle size by wet sieving and for organic content by combustion at $500^{\circ} \mathrm{C}$ (Murphey \& Fonseca 1995)

Tidal current speed. Current speed was recorded over a rising spring tide (approximately 6 h of the local semidiurnal tide) at each site by timing passage of a neutrally buoyant Cyalume ${ }^{\text {TM }}$ stick or food dye past a meter stick. Current speed and depth measurements were collected on October 5, 1990, starting at spring low tide. Measurements were taken synoptically at all 18 sites; total water depth and mid-depth tidal current speed were monitored at a known position on the site until the tide turned and both the depth and current speed at each site stabilized on 2 successive measurements (separated by $-1 / 2$ h). At each station and sampling time, 3 replicate current speed measurements were taken and averaged. Maximum tidal current speed was then computed for each site.

Relative water depth measurements. To compare water depths and potential exposure to waves among sites, we established a common relative datum based on the maximum height of barnacle encrustation that extended fully around the permanent corner stakes at each site. Given that all sites had roughly equivalent salinities and were equidistant from inlets, the timeaveraged zonation expressed by the barnacles should provide a useful, common datum in order to compare time-averaged water depths among sites. The height at which barnacles fully encirled one of the corner stakes was recorded at the time of each survey and was added to all depth measures to provide the relative water depth value for each survey point within a site. The barnacle height datum was also used to compare heights of seagrass beds versus unvegetated areas within sites.

Wave exposure computations. Wind data were obtained from a recording anemometer at $10 \mathrm{~m}$ height at Cape Lookout, North Carolina (National Ocean Survey), a location within $17 \mathrm{~km}$ of all study sites. We uti- 
lized wind velocities that exceeded $95 \%$ of the velocities observed during the study period (>10 $\mathrm{m} \mathrm{s}^{-1}$; exceedance winds, Keddy 1982) in computation of our relative exposure indices (REI). All wind speed observations less than the exceedance speed were stripped from the data set and the remaining values were used to calculate the maximum wind speed $(V)$, which was a grand mean [mean of the monthly means of daily maximum wind speeds $\left.\left(\mathrm{m} \mathrm{s}^{-1}\right)\right]$. The initial computation of daily maximum wind speeds were computed from a base data set of hourly measurements of wind speed and direction. All wind observations for 3 yr prior to the survey time were used in the computation. We used the 3 prior years of wind data because all seagrass shoots at our sites would have been produced within that time period (the life span for both Halodule wrightii and Zostera marina in this area is most frequently 2 yr or less; authors' unpubl. data). Thus, 3 yr would likely be a sufficient period of time over which to average effects of waves and tidal current speeds on growth of the plants and the bed forms they create. A relative wave exposure index (REI) was calculated using a macro written in ARCINFO for each site using the method of Keddy (1982) as adapted by Murphey \& Fonseca (1995):

$$
\mathrm{REI}=\sum_{i=1}^{8}\left(V_{i} \times P_{i} \times F_{1}\right)
$$

where $i=i$ th compass heading ( 1 to $8[N, N E$, E, etc.], in $45^{\circ}$ increments), $V=$ average monthly maximum wind speed in $\mathrm{ms}^{-1}, P=$ percent frequency which wind occurred from the $i$ th direction, and $F=$ effective fetch $(\mathrm{m})$.

Fetch was defined as the distance from the site to land along a given compass heading (Shore Protection Manual 1977). Effective fetch was computed by having the ARCINFO macro measure fetch along 4 lines radiating out from either side of the $i$ th compass heading with a spacing of $11.25^{\circ}$, and along the $i$ th heading $(n=$ 9). Effective fetch was then calculated in the macro by averaging the product of each of the 9 lines $\times$ cosine of the angle of departure from the $i$ th heading. This weighting of multiple fetch measures for each compass heading helps account for irregularities in shoreline geometry that could misrepresent the potential of wind wave development from a given compass heading (Shore Protection Manual 1977).

Data analysis. Percent bottom coverage by seagrass was calculated by dividing the total number of $1 \mathrm{~m}^{2}$ observations on which seagrass $\left(1 \mathrm{~m}^{2}=1\right.$ pixel) was recorded by the total area of the survey plot $\left(2500 \mathrm{~m}^{2}\right)$. Seagrass bed perimeter/area ratio (P/A) was determined by graphing cover ( $1 \mathrm{~m}^{2}$ pixel resolution) over the $50 \times 50$ survey plot and counting all pixel edges contiguous with non-vegetated areas, excluding plot boundaries. Those seagrass patches that had discrete boundaries within each $2500 \mathrm{~m}^{2}$ study plot were identified, and the size (vegetated area only) and number of patches which contained openings within the patch boundaries ( $1 \mathrm{~m}^{2}$ minimum size) were recorded. We interpreted the appearance of openings within a patch to signal the potential initiation of patch fragmentation; we termed such patches 'halos'

Simple linear regressions and $95 \%$ confidence limits were determined and plotted for habitat attributes for all sites from the 4 sampling dates. Dependent variables were shoot density, above- and belowground biomass, \% flowering shoots (for Zostera marina), sediment \% silt-clay and \% organic matter content, number of patches with halos and their size, \% bottom cover by seagrass, total linear edge of beds, P/A ratio, the ratio of Halodule wrightii to $Z$. marina shoots, and difference in average water depth of vegetated versus unvegetated pixels, by site. Dependent variables were correlated with REI, maximum tidal current speed and relative water depth using Spearman rank correlation coefficients with sites as independent observations (SAS 1989). Principal components analysis (PCA) was used to determine if sites could be grouped by habitat attributes. Habitat attributes were included in PCA after transformation [ln(value+1); excluding data presented as ratios]. Stepwise multiple linear regression was also used to evaluate the relative roles of REI, current velocity and depth for predicting habitat attributes, including blocking variation induced by sampling year and season after ln(value+1) transformation to improve homogeneity of variance.

\section{RESULTS}

\section{Observations of seagrass bed spatial arrangement}

Spatial representations produced by mapping of seagrasses indicated bed patterns that ranged from complete cover to isolated seagrass patches of $1 \mathrm{~m}^{2}$ separated by several meters of unvegetated sand (Fig 1), Some beds were formed of irregularly shaped larger patches of seagrass, connected by narrow corridors of seagrass. Beds that consistently appeared fragmented had more pronounced vertical relief, with vegetated portions appearing as dune-like structures (authors' pers. obs.)

\section{Environmental setting}

During summer (May-June) and early fall (September) sampling over the 2 yr study period (1991-1992), water temperature among the 18 sites averaged $26.8^{\circ} \mathrm{C}$ 

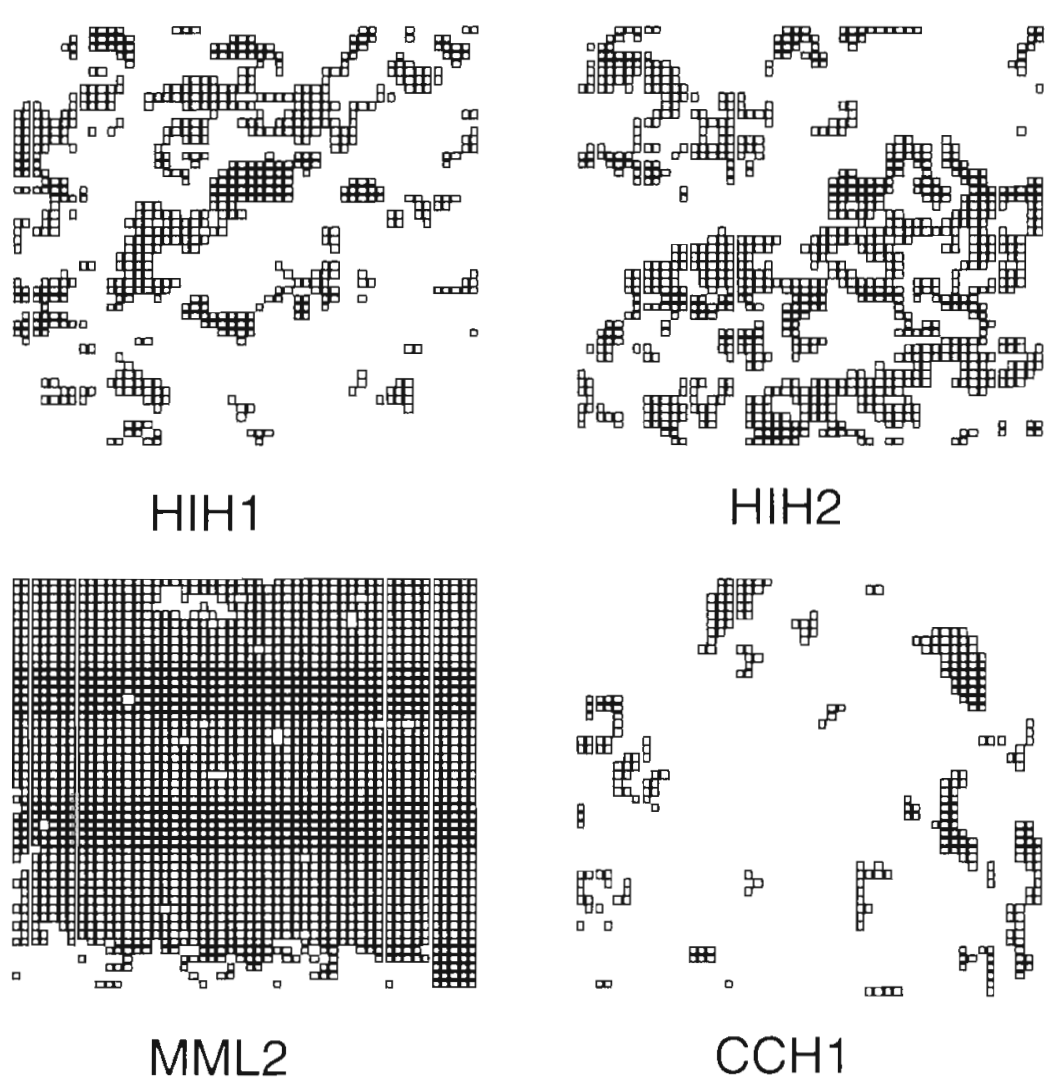

Fig. 1. Maps $(50 \times 50 \mathrm{~m})$ of 4 representative North Carolına study sites at $50 \mathrm{~m}$ scale with $1 \mathrm{~m}$ resolution showing variation in seagrass coverage. Each square represents a $1 \mathrm{~m}^{2}$ area of seagrass cover; unvegetated areas are unmarked. Site HIH1. $36 \%$ cover, relative exposure index (REI) of $-3.78 \times 10^{\mathrm{b}}$, maximum tidal current speed $(U)$ of $30 \mathrm{~cm} \mathrm{~s}^{-1}$ and a sediment organic content (OM) of $1.4 \%$; site MML2: $89 \%$ cover, REI $\approx 6.19 \times 10^{5}, U=17 \mathrm{~cm} \mathrm{~s}^{-1}, \mathrm{OM}=2.0 \%$; site HIH2: $36 \%$ cover, $R E I \approx 4.83 \times 10^{\circ}, U=23 \mathrm{~cm} \mathrm{~s}^{-1}, \mathrm{OM}=1.2 \%$; site $\mathrm{CCH} 1: 13 \%$ cover, $\mathrm{REI}=$ $5.09 \times 10^{6}, U=36 \mathrm{~cm} \mathrm{~s}^{-1}, \mathrm{OM}=1.0 \%$

\section{Seagrass species composition and biomass}

Across the 4 survey times, Halodule wrightii shoot density averaged $\sim 1633$ shoots $\mathrm{m}^{-2}$ among sites (Table 1), with little seasonal fluctuation. $H$. wrightii aboveground biomass averaged $\sim 327 \mathrm{~g} \mathrm{dw}^{-2}$ Zostera marina shoot density averaged -278 shoots $\mathrm{m}^{-2}$ while aboveground biomass averaged $\sim 61 \mathrm{~g} \mathrm{dw} \mathrm{m}^{-2}$. Z marina shoot density and aboveground biomass were -17 and $\sim 18 \%$ of those of $\mathrm{H}$. wrightii, respectively. Living belowground biomass was not distinguished among species, and ranged between 15 and $1041 \mathrm{~g} \mathrm{dw} \mathrm{m}^{-2}$, with a mean across sites and seasons of $\sim 210 \mathrm{~g} \mathrm{dw}$ $\mathrm{m}^{-2}$.

\section{Patch and halo formation}

From a total of 1566 isolated patches detected in the surveys, $124(\sim 8 \%)$ exhibited halo formation. Patches without halos were an average of $33 \mathrm{~m}^{2}$ (SE 6.76) while patches with halo formation averaged $541 \mathrm{~m}^{2}$ (SE 68.83). There was no correlation between number of halos per site or halo or size with REI or current speed (both comparisons: $\mathrm{p}>0.05 ; \mathrm{r}^{2}>0.10$ ).

\section{Correlation analysis}

$0.58 \mathrm{~m}$ (SE 0.02). Maximum tidal current speeds ranged from 5 to $37 \mathrm{~cm} \mathrm{~s}^{-1}$ among study sites.

Mean wind velocity ranged from -4 to $7 \mathrm{~m} \mathrm{~s}^{-1}$ depending upon direction (Fig. 2a), with strongest mean wind velocity from the northeast. The top $5 \%$ of wind velocities ranged between $\sim 10.5$ and $20 \mathrm{~m} \mathrm{~s}^{-1}$, and the average maximum speed was almost equal among directions (Fig. 2b). Overall, wind tended to come from northeasterly and southwesterly directions (Fig 2c). Northeasterly directions were more frequently experienced during winter months while southwesterly winds were typically a summertime event (data not shown). The frequency distribution of exceedence winds (Fig, 2d) revealed that $\sim 67 \%$ of these wind observations were from the nor therly and northeasterly directions, meaning that seagrass beds with long north and northeasterly fetches would be expected to have high susceptibility to disturbance by exceedence wind events.
REI, current speed and mean relative water depth were compared with several seagrass bed parameters (Table 2) using the $50 \times 50 \mathrm{~m}$ sites as replicates. Shoot density was positively correlated with REJ and mean depth. Aboveground biomass $\left(g \mathrm{dw} \mathrm{m}^{-2}\right)$ was not correlated with any independent variable. Conversely, belowground biomass was positively correlated with REI and increasing water depth. The ratio of Halodule wrightii to Zostera marina increased with increasing REI and mean depth. Flowering percentage in $Z$. marina was positively correlated with REI and mean depth. Sediment silt-clay and organic matter content and percent seagrass cover were negatively correlated with all 3 independent variables. $\mathrm{P} / \mathrm{A}$ increased with all independent variables (perimeter, or linear edge, alone increased only with current speed), indicating a greater degree of frag- 
a.
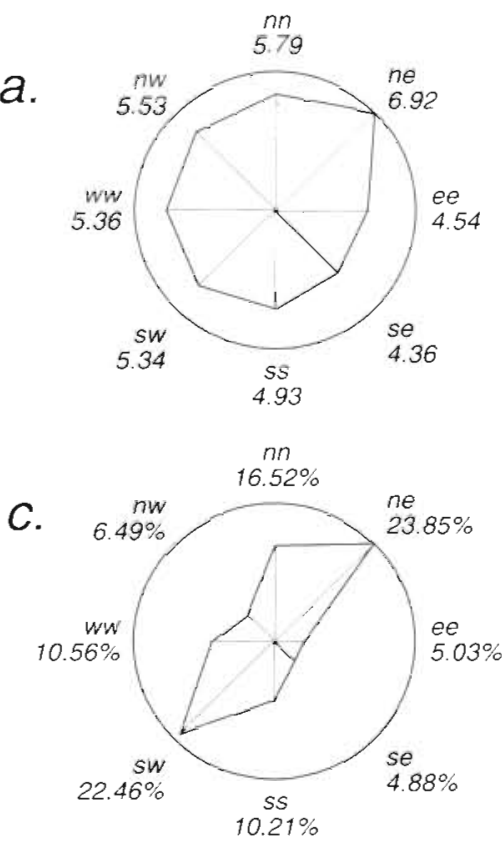

$b$.

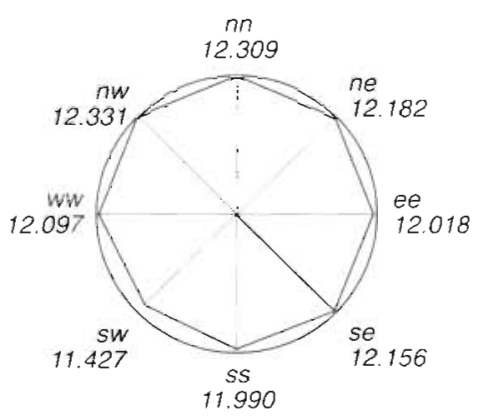

d.

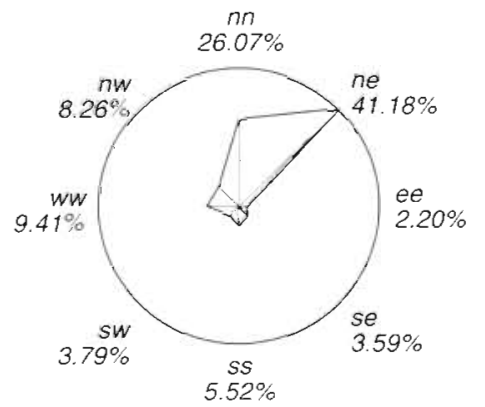

Fig. 2. Windspeed data from 1988 through 1992 based on data from NOAA weather station, Cape Lookout, North Carolina. $n n=$ North, ne = northeast, ee $=$ east,, $\mathrm{se}=$ southeast, $\mathrm{ss}=$ south, $\mathrm{sw}=$ southwest, $\mathrm{ww}=$ west, $\mathrm{nw}=$ northwest. (a) Mean monthly windspeed in $\mathrm{m} \mathrm{s}^{-1}$ for each of the 8 major compass headings. (b) Mean maximum monthly windspeed in $\mathrm{m} \mathrm{s}^{-1}$ for each of the 8 major compass headings. (c) Percentage of time wind was blowing from each compass heading. (d) Percent of exceedance winds (top $5 \%$ of observed maximum monthly wind speeds) by compass heading

mentation of coverage with physical energy and depth. Difference in height among seagrass-covered and unvegetated portions of a site was positively correlated only with REI, indicating that more mounded seagrass bedforms occurred with increasing wave exposure

\section{Graphical relationships}

Graphical representations of both landscape and sedimentary characteristics versus physical setting provide additional insight into the nature of those relationships. Only dependent variables with some visual indication of a threshold response are presented. The correlation strength and sign of the relationships between seagrass bed attributes and physical setting are given in Table 2 .

Percent cover values show marked scatter at low REI but tend to be more strongly aggregated at higher REI (Fig. 3a). A similar trend is obvious for percent cover and maximum current velocity (Fig. 3b). Plots of $P / A$ versus $R E I$ and current velocity also display data aggregation with higher REI and current speed
(Fig. $4 \mathrm{a}, \mathrm{b})$. There was no obvious pattern of the Halodule wrightiil Zostera marina ratio with REI (not shown). Plots of sedimentary characteristics versus REI and current velocity (Fig 5a-d) revealed patterns similar to that for percent cover, i.e. increased aggregation of values at high REI and current velocity. These changes in the range of variation in sedimentary and other landscape features occur consistently at a REI of $\sim 3$ to $3.6 \times 1.0^{6}$ and current speeds between 25 and $30 \mathrm{~cm} \mathrm{~s}^{-1}$.

We grouped sites as either low $(<50 \%)$ or high ( $\geq 50 \%$ ) cover, following the convention of Sousa (1985) for additional analyses; we also generalized these 2 groups to represent high and low flow regimes, respectively. Apparent thresholds and data aggregation above and below these threshold values were relatively consistent across seasons. Coefficients of variation (CV) for habitat attributes such as percent cover were within the same order of magnitude among high and low regimes, but high flow groups tended to have a slightly higher value (e.g. percent cover $=63.55$ and 33.42 for CV REI $>3 \times 10^{6}$ and REI $<3 \times 10^{6}$, respectively; percent cover $\mathrm{CV}=59.48$ and 34.19 for current speed $>25 \mathrm{~cm} \mathrm{~s}^{-1}$ and current speed $<25 \mathrm{~cm}$ $\mathrm{s}^{-1}$, respectively), which also reflects a smaller variation among sampling dates in high versus low flow regimes.

\section{Principal components analysis}

In PCA using 11 dependent variables, 4 principal components had eigenvalues higher than 1 (Table 3 ), accounting for $-78 \%$ of the standardized variance. The first principal component accounted for $\sim 37 \%$ of the standardized variance, with coverage, P/A ratio, sediment silt-clay and organic matter content having highest loadings on the first eigenvector (Table 3). Classification of sites as high and low flow regimes (based on percent cover, see above) indicates strong grouping by regime (Fig. 6a, b) and supports the notion of an environmental threshold. Shoot density and above- and belowground biomass loaded most heavily on the second eigenvector, which accounted for an additional $19 \%$ of the variance. The third principal component accounted for $\sim 13 \%$ of the variance, with linear edge, 
Table 1 Summary statistics of physical factors and habitat attributes for all survey periods. REI = relative exposure index in $1000 \mathrm{~s} ; \mathrm{Zm}=$ Zostera marina; H. $w$. = Halodule wrightii Abvg. = aboveground; Blwg. = belowground

\begin{tabular}{|c|c|c|c|}
\hline Variable & Minimum & Maximum & Mean \\
\hline \multicolumn{4}{|l|}{ Spring 1991} \\
\hline $\mathrm{REI}$ & 534 & 5065 & 2453 \\
\hline Current speed $\left(\mathrm{cm} \mathrm{s}^{-1}\right)$ & 5 & 37 & 19 \\
\hline Edge $(\mathrm{m})$ & 0 & 1738 & 748 \\
\hline$\%$ silt-clay & 7 & 38 & 17 \\
\hline$\%$ organic & 0.5 & 4 & 2 \\
\hline Z.m density & 0 & 810 & 329 \\
\hline H.w. density & 0 & 5084 & 1542 \\
\hline Z.m. abvg. biomass (g) & 0 & 247 & 77 \\
\hline H.w. abvg biomass (g) & 0 & 3310 & 454 \\
\hline Blwg. biomass $(g)$ & 15 & 485 & 183 \\
\hline$\%$ flowering & 0.2 & 7 & 0.9 \\
\hline Patch area without halo & 1 & 2500 & 58 \\
\hline Patch area with halo & 4 & 1597 & 297 \\
\hline \multicolumn{4}{|l|}{ Fall 1991} \\
\hline REI & 534 & 5069 & 2463 \\
\hline Current speed $\left(\mathrm{cm} \mathrm{s}^{-1}\right)$ & 5 & 36 & 19 \\
\hline Edge $(\mathrm{m})$ & 0 & 1400 & 666 \\
\hline$\%$ silt-clay & 11 & 51 & 23 \\
\hline$\%$ organic & 0.4 & 5 & 2 \\
\hline Z.m. density & 0 & 442 & 185 \\
\hline H.w. density & 61 & 2982 & 1486 \\
\hline Z.m. abvg biomass $(\mathrm{g})$ & 0 & 85 & 21 \\
\hline H.w. abvg. biomass (g) & 4 & 1547 & 4 \\
\hline Blwg biomass $(g)$ & 59 & 392 & 207 \\
\hline$\%$ flowering & 0.4 & 7 & 2 \\
\hline Patch area without halo & 1 & 2500 & 17 \\
\hline Patch area with halo & 8 & 2451 & 403 \\
\hline \multicolumn{4}{|l|}{ Spring 1992} \\
\hline REI & 535 & 5108 & 2480 \\
\hline Current speed $\left(\mathrm{cm} \mathrm{s}^{-1}\right)$ & 5 & 36 & 19 \\
\hline Edge $(m)$ & 0 & 1382 & 632 \\
\hline$\%$ silt-clay & 5 & 40 & 18 \\
\hline$\%$ organic & 0.4 & 4 & 1 \\
\hline Z.m. density & 0 & 1133 & 423 \\
\hline H.w. density & 0 & 6384 & 1976 \\
\hline Z.m. abvg. biomass $(g)$ & 0 & 611 & 131 \\
\hline H.w. abvg blomass (g) & 0 & 1113 & 219 \\
\hline Blwg bromass $(\mathrm{g})$ & 75 & 1041 & 285 \\
\hline$\%$ flowering & 0.1 & 2 & 0.5 \\
\hline Patch area without halo & 1 & 2500 & 25 \\
\hline Patch area with halo & 36 & 2488 & 851 \\
\hline \multicolumn{4}{|l|}{ Fall 1992} \\
\hline REI & 541 & 5115 & 2392 \\
\hline Current speed $\left(\mathrm{cm} \mathrm{s}^{-1}\right)$ & 5 & 36 & 19 \\
\hline Edge (m) & 0 & 1499 & 603 \\
\hline$\%$ silt-clay & 7 & 1499 & 603 \\
\hline$\%$ organic & 0.5 & 3 & 2 \\
\hline Z.m. density & 0 & 512 & 175 \\
\hline H.w. density & 0 & 4276 & 1531 \\
\hline Z.m. abvg biomass $(\mathrm{g})$ & 0 & 67 & 15 \\
\hline$H . w$. abvg biomass (g) & 0 & 738 & 215 \\
\hline Blwg biomass (g) & 40 & 287 & 167 \\
\hline$\%$ flowering & 0.1 & 0.7 & 0.2 \\
\hline Patch area without halo & 1 & 2500 & 33 \\
\hline Patch area with halo & 7 & 2443 & 613 \\
\hline
\end{tabular}

Table 2. Correlation matrix (Spearman rank correlation coefficients) of hubitat attributes with physical attributes of North Carolina study sites, all surveys combined. Only significant $(p<0.05)$ correlations have coefficients. $\mathrm{REI}=$ relative exposure index; H.w./Z.m. = Halodule wrightii/Zostera marina shoot ratio; $\mathrm{P} / \mathrm{A}=$ perimeter:area ratio; $\mathrm{OM}=$ sediment organic content; Ht difference $=$ difference in seafloor elevation in vegetated vs non-vegetated areas within study sites; Abvg. = aboveground; Blwg. = belowground

\begin{tabular}{|lrcc|}
\hline Attribute & REI & $\begin{array}{c}\text { Current } \\
\text { speed }\end{array}$ & $\begin{array}{c}\text { Relative } \\
\text { depth }\end{array}$ \\
\hline H.w.Z.m. & 0.38 & 0.23 & 0.44 \\
$\%$ cover & -0.57 & -0.80 & -0.40 \\
P/A ratio & 0.52 & 0.74 & 0.36 \\
$\%$ silt-clay & -0.75 & -0.61 & -0.56 \\
$\%$ OM & -0.71 & -0.57 & -0.45 \\
Edge & - & 0.40 & - \\
Ht difference & 0.26 & - & - \\
Shoot density & 0.41 & - & 0.49 \\
Abvg. biomass & - & - & - \\
$\%$ flowering & 0.29 & - & 0.31 \\
(Z. marina) & & & 0.54 \\
Blwg. biomass & 0.53 & - & \\
\hline
\end{tabular}

Table 3. Pruncipal components analysis of North Carolina seagrass habitat attributes. Prin = principal component. Eigenvector with highest loading for individual attributes is shown in bold. Abbreviations as in Table 2

\begin{tabular}{|lrrrr|}
\hline Attribute & Prin 1 & Prin 2 & Prin 3 & Prin 4 \\
\hline H.w/Z.m. & 0.21 & 0.03 & $\mathbf{- 0 . 5 7}$ & 0.06 \\
$\%$ cover & $\mathbf{- 0 . 4 1}$ & 0.21 & 0.21 & 0.11 \\
P/A ratio & $\mathbf{0 . 4 0}$ & -0.27 & 0.02 & 0.06 \\
$\%$ silt-clay & $-\mathbf{0 . 3 8}$ & -0.14 & 0.23 & 0.03 \\
$\%$ OM & $\mathbf{- 0 . 3 7}$ & -0.07 & 0.28 & 0.14 \\
Edge & 0.18 & -0.24 & $\mathbf{0 . 6 2}$ & 0.32 \\
Ht difference & 0.08 & 0.00 & 0.49 & $-\mathbf{0 . 7 5}$ \\
Shoot density & 0.19 & $\mathbf{0 . 4 7}$ & $\mathbf{- 0 . 1 0}$ & -0.30 \\
Abvg. biomass & 0.06 & $\mathbf{0 . 5 3}$ & 0.18 & 0.28 \\
Blwg. biomass & 0.23 & $\mathbf{0 . 4 0}$ & 0.38 & 0.05 \\
\% flowering & 0.15 & $\mathbf{- 0 . 0 8}$ & $\mathbf{0 . 5 9}$ & 0.15 \\
\hline
\end{tabular}

Halodule wrightii/Zostera marina shoot ratio, and flowering loading most heavily. The fourth principal component accounted for $-10 \%$ of the variance, with site-specific height difference among vegetated and unvegetated pixels loading most heavily.

\section{Multiple regression analysis}

Stepwise multiple linear regression, used to predict habitat attributes as a function of REI, maximum current speed and water depth (Table 4), indicated that REI loaded first for Halodule wrightii/Zostera marina 

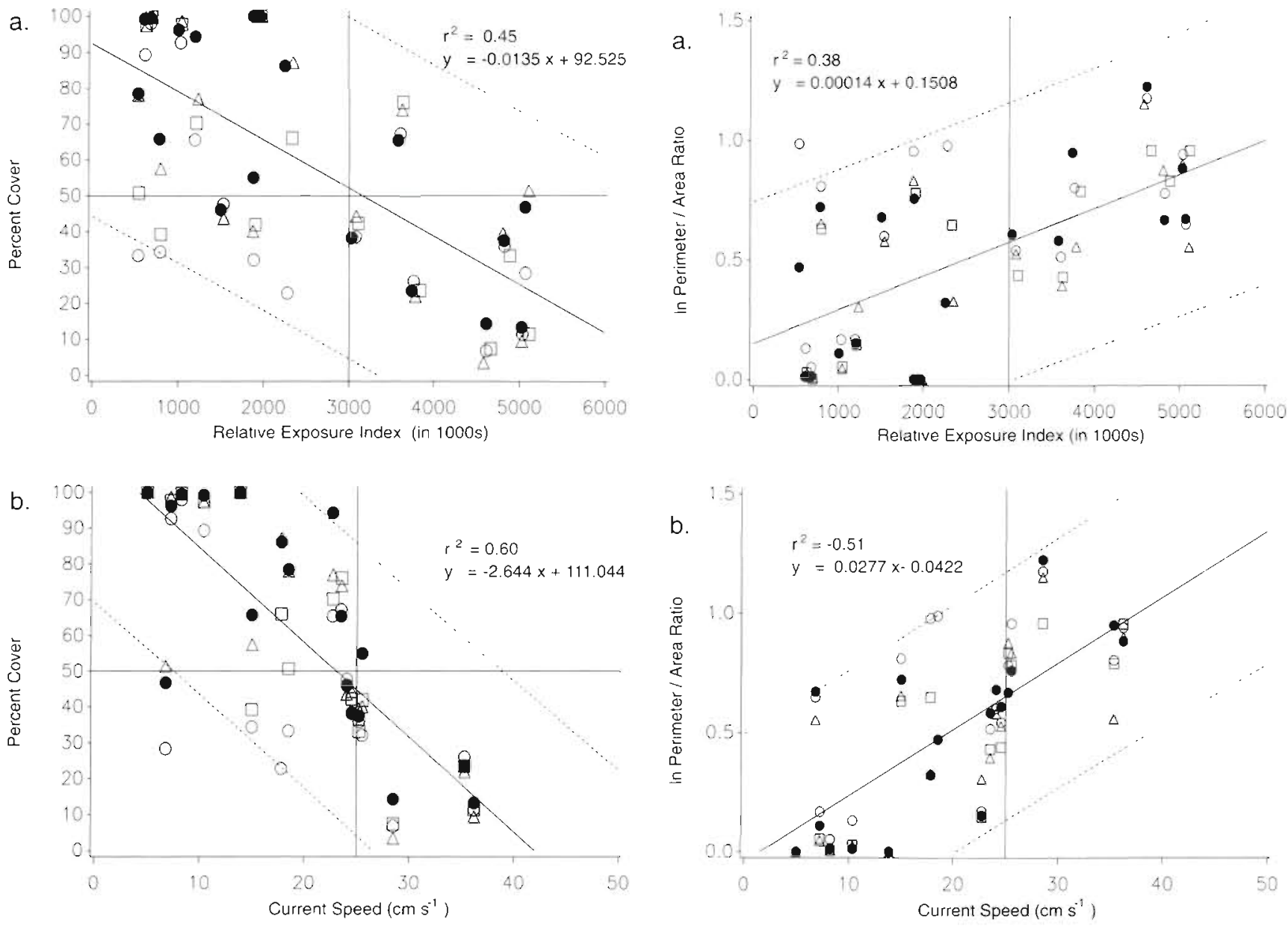

Fig. 3. Linear regressions and $95 \%$ confidence limits for percent cover as a function of (a) relative exposure index (REI) and (b) maximum (tidal cycle) current velocity. (-) May 1991; (O) November 1991.; ( $\Delta$ ) May 1992; (ㅁ) November 1992. Vertical line drawn at REI $=3 \times 10^{5}$ indicates potential threshold response; horizontal line drawn at $50 \%$ cover

Fig. 4. Linear regressions and $95 \%$ confidence limits for natural-log $(\ln )$ transformed ratio of bed perimeter to seagrass bed area $\left(\mathrm{m}^{2}\right)$ as a function of (a) relative exposure index (REI) and (b) maximum (tidal cycle) current velocity. Symbols and vertical line as in Fig. 3

Table 4. Stepwise multiple linear regression $[\ln (x+1)$-transformed data $]$ of habitat attributes loaded on REI, current speed and water depth. Model entry level $=p<0.15$. All values are significant at $p<0.05$. Abbreviations as in Table 2

\begin{tabular}{|lcccc|}
\hline $\begin{array}{l}\text { Dependent } \\
\text { variable }\end{array}$ & $\begin{array}{c}\text { REI partial } \\
\mathrm{r}^{2}\end{array}$ & $\begin{array}{c}\text { Speed partial } \\
\mathrm{r}^{2}\end{array}$ & $\begin{array}{c}\text { Depth partal } \\
\mathrm{r}^{2}\end{array}$ & $\begin{array}{c}\text { Model } \\
\mathrm{r}^{2}\end{array}$ \\
\hline H.w./Z.m. & 0.16 & - & - & 0.16 \\
$\%$ cover & 0.07 & 0.54 & - & 0.61 \\
P/A ratio & 0.05 & 0.4 .4 & - & 0.49 \\
$\%$ silt-clay & 0.66 & 0.02 & - & 0.68 \\
$\%$ OM & 0.50 & - & - & 0.50 \\
Edge & - & 0.17 & - & 0.17 \\
Ht difference & 0.06 & - & - & 0.06 \\
Shoot density & - & - & -27 & 0.27 \\
Abvg. biomass & - & - & - & - \\
Blwg. biomass & 0.11 & - & - & 0.36 \\
$\%$ flowering & 0.07 & - & & 0.07 \\
\hline
\end{tabular}

ratio, sediment variables, sediment height difference and $Z$. marina flowering while current speed. loaded first for \% cover, $\mathrm{P} / \mathrm{A}$ ratio and total edge. Relative water depth loaded best for shoot density and belowground biomass. The best model $r^{2}$ value was 0.68 ; often most of the variance in a habitat attribute remained unexplained. Blocking for year or season did not improve the results. In general, pixelderived data (e.g. cover, edge) or direct indicators of the depositional environment (e.g. sediment silt-clay and organic content) were better predicted by physical setting than plant attributes (e.g. biomass, density, flowering), although these plant attributes displayed significant correlation with physical setting (Table 4 ). 



Fig. 5. (a, b) Linear regressions and $95 \%$ confidence limits for sediment organic matter content as a function of (a) relative exposure index (REI) and (b) maximum (tidal cycle) current velocity. (c, d) Linear regressions and 95" confidence limits for percent silt-clay as a function of (c) REI and (d) maximum (tidal cycle) current velocity. Symbols and vertical line as in Fig. 3

a.

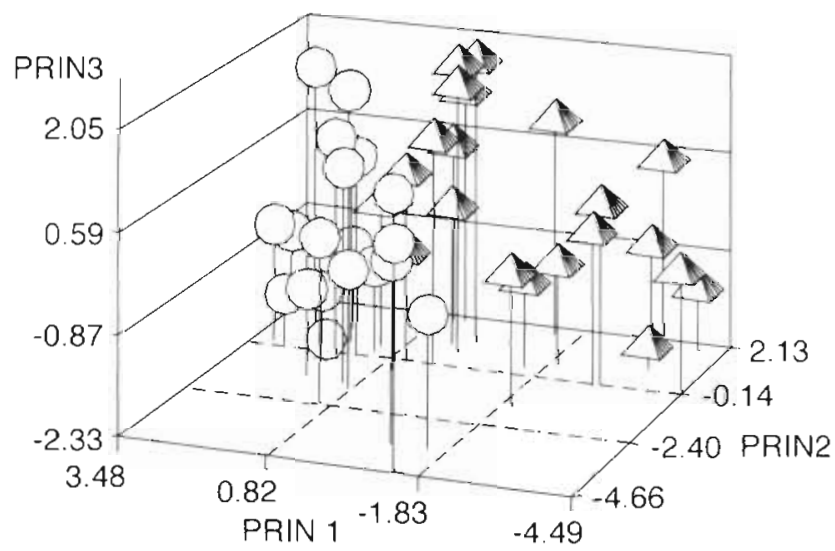

b.

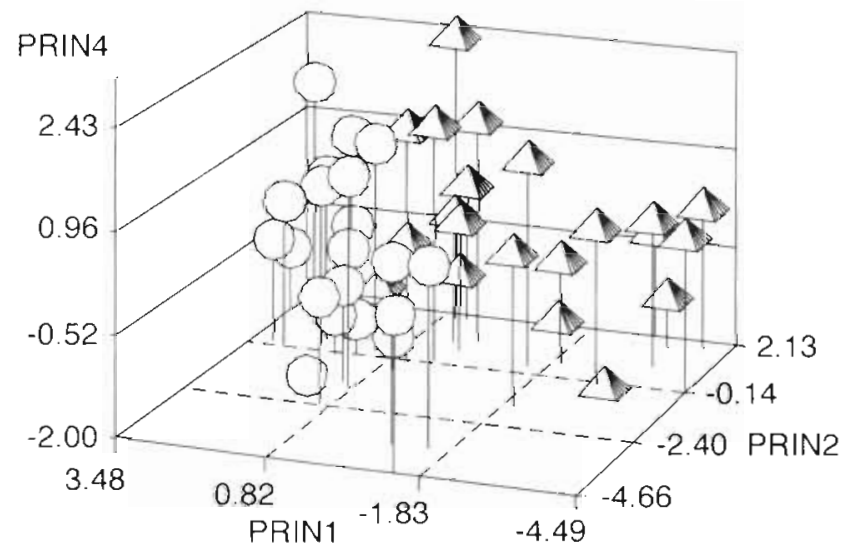

Fig. 6. Three dimensional plots showing eigenvalues (a) for the first 3 significant prunciple components (Prin) and (b) for principle components 1, 2, and 4 (the remaining significant principal component). Balls: sites with $<50 \%$ seagrass cover. Pyramids: sites with $>50 \%$ seagrass cover 


\section{DISCUSSION}

Although the relationship between seagrass bed coverage, shape and physical setting has long been proposed (Ginsberg \& Lowenstam 1958, den Hartog 1971, Patriquin 1975, Orth 1977, Kirkman \& Kuo 1990), our data quantify more specifically the association of structural attributes of seagrass beds with hydrodynamic processes (REI, and tidal current speed) and physical setting (water depth). Seagrass beds which we surveyed displayed a gradient of cover from continuous to semi-continuous to widely dispersed discrete patches. Examination of (tidal) current speeds, REI and relative water depths revealed strong correlative evidence that physical processes influenced these landscape-scale features of seagrass beds. Seagrass bed coverage, shape (P/A ratio), sediment composition and some attributes of the plants themselves at the submeter scale (belowground biomass, shoot density, flowering) all were also related to physical setting Moreover, effects of current speed were reflected in their high loading in the multiple regression analyses. However, in the absence of strong, sediment-moving current speeds, wave exposure alone may be inferred as a mechanism ordering seagrass bed attributes.

Hydrodynamic processes may influence seagrass landscape patterns via direct or indirect mechanisms and the results from our multiple regression analysis and PCA illustrate this point. Despite sampling over different seasons and years in North Carolina, prediction strength was high for a wide range of seagrass bed attributes based on current speed, REI and water depth. These attributes tended to group according to some aspects of seagrass bed pattern and sediment composition, shoot density and belowground biomass. The first eigenvector (Table 3 ) appears to describe seagrass bed attributes under the direct influence of REI and current speed, such as bed pattern and sediment particle size. The second eigenvector describes biomass allocation and shoot spacing (density). These attributes are probably modified indirectly by water motion via effects on the depositional environment such as sediment nutrient reserves (Kenworthy et al. 1982), sediment cohesiveness and penetrability by rhizomes (authors' pers. obs.), all of which may influence seagrass biomass allocation and shoot spacing (density). Other seagrass bed attributes, such as total linear edge of the seagrass bed and sediment height difference among vegetated and unvegetated portions of the sites, formed distinct groupings. These groupings may reflect other controlling processes such as bioturbation and the sediment stability afforded by seagrass cover. Through disruption of bed edges, bioturbation may increase total linear edge (Townsend \& Fonseca 1998), while differences in bottom elevation inside and outside seagrass beds may simply be the result of reduced erosion and increased sediment trapping by the seagrass canopy (Fonseca et al. 1983). Thus, the links seen here between seagrass bed arrangement, attributes and hydrodynamic setting may be further modified through a variety of previously identified biological and physical mechanisms.

Graphical representations indicated that seagrass bed attributes changed across gradients of current speed and REI and, in some cases, exhibited apparent thresholds of values with increasing hydrodynamic activity. What is striking is the high variation in percent cover, P/A ratio and sediment composition below a REI of $-3 \times 10^{6}$ and a current speed of $-25 \mathrm{~cm} \mathrm{~s}^{-1}$, while variance in these values was much reduced at higher REI and current speeds. Sediment movement, which is strongly influenced by local hydrodynamics, could lead to the observed data discontinuities in these seagrass bed attributes. The initiation of motion of sediment for the fine sand characteristic of the Beaufort, North Carolina area occurs at unidirectional current speeds of $\sim 25 \mathrm{~cm} \mathrm{~s}^{-1}$ (Fonseca \& Fisher 1986). This current speed coincided with data discontinuities for sediment silt-clay and organic content which are typical indicators of depositional processes. The same type of data discontinuity was noted for seagrass coverage (and $\mathrm{P} / \mathrm{A}$ ratio, particularly in response to current speed). Moreover, dramatic changes in sediment composition and seagrass coverage also occurred at a REI of $-3 \times 10^{6}$ Because REI is a proxy for wind-wave disturbance of the bottom, we suspect that REI values in the range of 3 to $3.6 \times 10^{6}$ represent a disturbance threshold for a number of seagrass bed attributes as does the $25 \mathrm{~cm} \mathrm{~s}^{-1}$ current speed.

We suggest that the link between hydrodynamic processes and seagrass bed attributes is the result of increasing mechanical disturbance with REI and current speed. A heightened disturbance level could reduce vegetative spreading of seagrass and inhibit seedling colonization, and it has been shown to result in decreased accumulation of fine sediments (Fonseca et al. 1983). In combination, these reductions could result in lower temporal variability in seagrass bed cover, shape (P/A ratio) and sediment composition, such as we have observed in this study. Additional study is required to determine if the effects of disturbance act indirectly through sedimentary processes or through direct impacts on seagrass vegetative colonization and seed transport, germination and rooting.

The existence of data thresholds in several seagrass bed attributes may aJso be exacerbated by landscapescale responses to disturbance. The $50 \%$ cover grouping that we used (sensu Sousa 1985) falls near to the coverage value of 59.28 (Gardner et al. 1987), above which landscape elements join ('percolating clusters'; 
With \& Crist 1995) and below which they tend to exist as discrete patches. At the $\sim 59 \%$ coverage, large landscape elements are joined by narrow corridors which may be particularly susceptible to disturbance. We posit that as these narrow corridors break, and contiguity of the habitat structure is lost (i.e. loss of landscape percolation), this may also represent a point at which the seagrass landscape loses a critical aspect of its physical stability, resulting in a rapid decline of coverage (and other habitat attributes) in the presence of waves and tidal currents. If loss of seagrass coverage resulting from disturbance in the form of increasing current speed and waves reaches a threshold whereby continued coverage loss (particularly of narrow corridors joining larger patches) results in an abrupt collapse of seagrass bed integrity, then this could explain why separation of sites based upon coverage (more or less than $50 \%$ coverage) under.PCA (Fig. 6) provided such a clear demarcation of data organization. These results hint that seagrass landscape contiguity, and not just the typical seagrass metrics such as biomass, shoot density, and canopy height, may be an appropriate measurement of landscape arrangement which may in turn have implications for vegetation persistence and concomitant effects on how organisms perceive and move through the landscape (sensu With \& Crist 1995).

The relationships of selected habitat characteristics to waves in this study were very similar to those seen in other studies of wave exposure for submerged plants. In marine systems, Pihl (1986) found a negative correlation between sediment particle size and organic content and exposure index, a relationship also found by Keddy (1982), Kautsky (1987) and Coops et al. (1991) in freshwater systems. Like Kautsky (1987), we found increased flowering of Zostera marina with wave exposure (e.g \% shoots flowering = $-5 \%$ at $\mathrm{REI} \approx 3.0 \times 10^{5}$ and $\sim 10 \%$ at $\mathrm{REI} \approx 3.0 \times 10^{6} \mathrm{j}$, which may be: a response to increased mortality risk (or higher chance of pollination) in those settings. Like Keddy (1982) and Coops et al. (1991), we found a trend for species to be segregated along a wave exposure gradient; Halodule wrightij was more likely to be found in exposed rather than sheltered areas, and the opposite was true for Zostera marina. Also, as seen by Kautsky (1987) and Coops et al. (1991), we found a trend of greater belowground biomass in exposed versus sheltered areas. In contrast, Chambers et al. (1991) found that Potamogeton pectinatus biomass decreased with current velocity, but here we found no correlation of aboveground biomass with any independent variables. Belowground biomass, a potential proxy for sediment stabilization by the plants, was, however, strongly positively correlated with REI.

Within our spatial arrangements of seagrasses we documented another source of bed heterogeneity- halo formation-likely arising from the centrifugal spread of seagrass patches, but perhaps exacerbated by disturbance. Halos were not found to correlated with REI or current speed but may be linked to seagrass age. Most of the patches with halos were large and appeared circular in shape. If this pattern was a result of radial growth of plants in these patches, then oldest plants would be likely to be found in the center area of a patch. However, if, as suggested by Fonseca \& Kenworthy (1987), seagrass shoot mortality and flow scouring of shoots in the center of a patch are responsible for halo-like formations, then one would expect halos to be most common in larger patches as suggested by our data. Patches with halos had a grand mean area that was substantially larger $\left(541 \mathrm{~m}^{2}\right)$, than the overall average patch size of $\sim 34 \mathrm{~m}^{2}$, and they had an estimated diameter of $\sim 26 \mathrm{~m}$, greater than average patch widths reported by Marba et al. $(1994 ; 18 \mathrm{~m})$ but similar to that reported by Duarte \& Sand-Jensen $(1990 ; 26 \mathrm{~m})$ for wave-exposed areas. Although patch size likely changes as a function of disturbance regime (here, likely a product of water depth, hydrodynamic activity, bioturbation and branching dynamics of different seagrass species), there appears to be some limit to patch size in high flow environments that prevents the eventual coalescence of the patches. The close coupling of sediment movement and seagrass bed pattern in high flow regimes has been addressed for some seagrass species, but the relationship of halo formation with disturbance over a range of flow regimes and the contribution to bed fragmentation through halo formation remain to be determined.

While our findings can be used to predict local seagrass pattern in terms of coverage, water depth can modulate REI and local current speeds, thereby influencing seagrass landscapes. Wave effects on landscape pattern are expected to be pronounced when shallow water waves (water depth $<1 / 2$ wavelength; shoal waters) can form. This relationship is supported by the negative correlations of water depth with seagrass coverage and the presence of fine sediments (Table 2). The relative influence of current speed, waves (exposure) and water depth on seagrass attributes is difficult to distinguish by use of correlation and remains problematic. Because of the modification of waves by water depth, a site located in shoal waters somewhat confounds REI measurements. Sites in shallow water far from the location where shoaling begins may need special evaluation to portray accurately the influence of REI, which does not consider bathymetric effects on waves along a fetch measurement. Thus, in some systems where shoaling is extensive, the relationship between seagrass coverage and exposure may depart from that observed here. 
Our approach herein includes only estimates of chronic disturbance as we utilized values of REI and current speeds based on monthly maxima. An assessment of the relative roles played by chronic versus acute disturbance in organizing seagrass spatial patterns has yet to be conducted. We assumed that chronic disturbance existed in at least seasonally predictable maxima of sediment transport, erosion of bed margins, sand abrasion, emersion and bioturbation. Our approach using an exposure index composed of monthly wind speed averages may not be sufficiently sensitive to effects of extreme wind events. In comparison, tidally driven currents are not given to extreme, unpredictable changes in their magnitude and in the time frame of this study, may have been more predictable than wind wave effects. We did not determine whether acute wind events periodically act to organize seagrass bed formation through extensive reductions in seagrass coverage, although some systems (e.g. Tampa Bay) can experience marked changes in cover after large storm events (Bell unpubl.). Extreme wind events (e.g. hurricanes) may ultimately provide a basis for large-scale and rapid changes in seagrass bed attributes upon which chronic waves and tidal currents may then act (see Gaines \& Denny 1993).

Our study offers insight into the nature of variation in a number of ecological processes in seagrass beds beyond that of predicting structural responses to physical setting. For example, disturbance regime and bed pattern have recently been linked to faunal utilization (Pihl 1986, Bell et al. 1994, Irlandi et al. 1995, Irlandi 1996), and our earlier discussion comparing freshwater studies to ours also indicates that identification of physical setting, including hydrodynamic conditions, may provide at least a partial explanation for some of the variation in seagrass ecosystem attributes (seagrass species composition, flowering, cover, sediment composition, shoot density, belowground biomass), many of which have been shown to influence ecological processes in seagrass beds, such as population maintenance (Orth et al. 1994), feeding (Bell et al. 1994) and predation (Heck \& Crowder 1994). However, to aid in interpretation of the quantitative linkage among REI, currents and water depth with landscape pattern and other habitat attributes, greater spatial and temporal resolution of mechanical forces, including the individual shoot scale, may be requisite. In the interim, we conclude that the present approach seems to provide a useful context for evaluating at least timeaveraged attributes of seagrass beds in a geographically enclosed setting.

Acknowledgements. We thank our many colleagues who aided us both in the field and the lab; special thanks go to $M$. Crawford, M. O. Hall, S. Jensen, W. J. Kenworthy, M.
LaCroix, D. Meyer, B. Robbins, E. Townsend, and P. Whitfield. Reviews by R. Ferguson, J. Kenworthy, B. Robbıns, G. Thayer, Evamaria $W$. Koch and 3 anonymous reviewers greatly improved the manuscript. We are indebted to N. Maggi Kelly for her guidance and labor on the ARCINFO macro development. This work was supported by NOAA's Coastal Ocean Program, EHP-23 to the authors, as well as matching support by the authors' respective affiliations.

\section{LITERATURE CITED}

Armstrong SL (1989) The behavior in flow of the morphologically variable seaweed Hedophyllum sessile (CAg) Setchell. Hydrobiologia 183:115-122

Bell SS, Hall MO. Fonseca MS (1994) Evaluation of faunal and floral attributes of seagrass beds in high and low energy regimes: a geographic comparison. In: Dyer KR, D'Elia CF (eds) Changes in fluxes in estuaries: implications from science to management. Olsen and Olsen Press, Fredensborg, p 267-272

Chambers PA, Prepas EE, Hamilton HR, Bothwell ML (1991) Current velocity and its effect on aquatic macrophytes in flowing waters. Ecol Appl 1:249-257

Charters AC, Neushul M, Barilotti C (1969) The functional morphology of Eisenia arborea. Proc Int Seaweed Symp 6: $89-105$

Coops H, Boeters R, Smit H (1991) Direct and indirect effects of wave attack on helophytes. Aquat Bot 41:333-352

den Hartog $C$ (1971) The dynamic aspect in the ecology of seagrass communities. Thalassia Jugosl 7:101-112

Duarte CM, Kalff J (1990) Patterns in the submerged macrophyte biomass of lakes and the importance of the scale of analysis in the interpretation. Can J Fish Aquat Sci 47: $357-363$

Duarte CM, Sand-Jensen K (1990) Seagrass colonization: patch formation and patch growth in Cymodocea nodosa. Mar Ecol Prog Ser 65:193-200

Ferguson RL, Wood LL, Pawlak BT (1991) SAV habitat in 1985 and 1988: Cape Lookout to Drum Inlet, North Carolina. NOAA-Coastal Ocean Program Chart, NOAA, NMFS/ NOAA, 101 Pivers Island Rd, Beaufort, NC

Fonseca MS (1996a) Scale dependence in the study of seagrass systems. In: Kuo J, Phillips RC, Walker DI, Kirkman $\mathrm{H}$ (eds) Proc Int Seagrass Biology Workshop, 25-29 January, Rottnest Island, Australia. Faculty of Sciences, Univ of Western Australia, Nedlands, WA, p 95-104

Fonseca MS (1996b) A review of the role of seagrasses in nearshore sedimentary processes. In: Roman C, Nordstrom K (eds) Estuarine shores: hydrological, geomorphological and ecological interactions. Blackwell, Boston, p 261-268

Fonseca MS, Fisher JS (1986) A comparison of canopy friction and sediment movement between four species of seagrass with reference to their ecology and restoration. Mar Ecol Prog Ser 29:15-22

Fonseca MS, Kenworthy WJ (1987) Effects of current on photosynthesis and distribution of seagrasses. Aquat Bot 27: $59-78$

Fonseca MS, Zieman JC, Thayer GW, Fisher JS (1983) The role of current velocity in structuring seagrass meadows. Estuar Coast Shelf Scl 17:367-380

Gaines SD, Denny MW (1993) The largest, smallest, highest, lowest, longest, and shortest: extremes in ecology. Ecology $74: 1677-1692$

Gardner RH, Turner MG, O'Neill RV (1987) Neutral models 
for the analysis of broad-scale landscape pattern. Landscape Ecol 1:19-28

Ginsberg RN, Lowenstam HA (1958) The influence of marine bottom communities on the deposition environment of sediments. J Geol 66:310-318

Heck \& Crowder (1994) Habitat structure and predator-prey interactions in vegetated aquatic systems. In. Bell SS, McCoy ED, Mushinsky HR (eds) Habitat structure: the physical arrangement of objects in space. Chapman \& Hall, New York, p 281-299

Irlandi EA (1996) The effects of seagrass patch size and energy regime on growth of a suspension-feeding bivalve. J Mar Res 54:161-185

Irlandi EA, Ambrose WG, Orlando BA (1995) Landscape ecology and the marine environment: how spatial configuration of seagrass habitat influences growth and survival of the bay scallop. Oikos 72:307-313

Kautsky L (1987) Life-cycles of three populations of Potamogeton pectinatus L., at different degrees of wave exposure in the Asko area, northern Baltic proper Aquat Bot 27:177-186

Keddy PA (1982) Quantifyng within-lake gradients of wave energy: interrelationships of wave energy, substrate particle size and shoreline plants in Axe Lake, Ontario. Aquat Bot 14:41-58

Keddy PA (1983) Shoreline vegetation in Axe Lake, Ontarı: effects of exposure on zonation patterns. Ecology 64 : $331-344$

Kenworthy WJ, Zieman JC. Thayer GW (1982) Evidence for the influence of seagrass on the benthic nitrogen cycle in a coastal plain estuary near Beautort. North Carolina (USA). Oecologia 54:152-158

Kirkman H, Kuo J (1990) Pattern and process in southern Western Australian seagrasses. Aquat Bot 37:367--382

Koehl MAR (1986) Seaweeds in moving water: form and mechanical function. In: Givnish TJ (ed) On the economy of plant form and function. Cambridge University Press, p 603-634

Koehl MAR, Alberte RS (1988) Flow, flapping, and photosynthesis of macroalgae: functional consequences of undulate blade morphology. Mar Biol 99:435-444

Levin PS, Mathieson AC (1991) Variation in a host-epiphyte relationship along a wave exposure gradient. Mar Ecol Prog Ser $77: 271-278$

Lovett-Doust L (1981) Population dynamics and local specialization in a clonal perennial (Ranunculus repens): 1. The dynamics of ramets in contrasting habitats. J Ecol 69: $743-755$

Marba NJ, Cebrian S, Enriquez S, Duarte CM (1994) Migration of large-scale subaqueous bedforms measured using seagrass (Cymodocea nodosa) as tracers. Limnol Oceanogr 39:126-133

Editorial responsibulity: Kenneth Heck (Contributing Editor), Dauphin Island, Alabama, USA
Murphey PE, Fonseca MS (1995) Role of high and low enrrgy seagrass beds as nursery ares for Penaeus duorarum in North Carolina. Mar Ecol Prog Ser 121:91-98

O'Gower AK, Wacasey JW (1967) Animal communities associated with Thalassia, Diplanthera, and sand beds in Biscayne Bay. I. Analysis of communities in relation to water movement. Bull Mar Sci 17:175-210

Orth RJ (1977) The importance of sediment stability in seagrass communities. In: Coull BC (ed) Ecology of marine benthos. Univ South Carolina Press, Columbia, p 281-300

Orth RJ, Luckenbach M. Moore KA (1994) Seed dispersal in a marine macrophyte: implications for colonization and restoration. Ecology 75:1927-1939

Patnquin DG (1975) 'Migration' of blowouts in seagrass beds at Barbados and Carriacou, West Indies and its ecological and geological applications. Aquat Bot 1:163-189

Philippart CJM (1994) Interactions between Arenicola marina and Zostera noltii on a tidal flat in the Wadden Sea. Mar Ecol Prog Ser 111:251-257

Pihl L (1986) Exposure, vegetation and sediment as primary factors for mobile epibenthic faunal community structure and production in shallow marine soft bottom areas. Neth $\mathrm{J}$ Sea Res 20:75-83

Robbins B, Bell SS (1994) Seagrass landscapes: a terrestrial approach to the marine subtidal environment. Trends Ecol Evol 9:301-304

SAS (1989) SAS/STAT Users Guide, Version 6, 4th edn, Vol 2. SAS Institute, Cary, NC

Shore Protection Manual (1977) U.S. Army Coastal Engineerung Research Center, Ft Belvoír, VA

Sousa WP (1985) Disturbance and patchy dynamics on rocky intertidal shores. In: White PS, Pickett STA (eds) The ecology of natural disturbance and patch dynamics. Academic Press, New York, p 101-124

Suchanek TH (1.983) Control of seagrass communities and sediment distribution by Callianassa (Crustacea, Thalassinidea) bioturbation. J Mar Res 41:281-298

Sutherland WJ, Stillman RA (1988) The foraging tactics of plants. Oikos 52:239-244

Thayer GW, Kenworthy WJ, Fonseca MS (1984) The ecology of eelgrass meadows of the Atlantic coast: a community profile. U.S. Fish and Wildlife Service, FWS/OBS-84/02

Townsend EC, Fonseca MS (1998) Bioturbation as a potential mechanism influencing spatial heterogeneity of North Carolina seagrass beds. Mar Ecol Prog Ser 169:123-132

Valentine JF, Heck KL, Harper P, Beck M (1994) Effects of bioturbation in controlling turtlegrass Thalassia testudinum (Banks ex Konıg) abundance: evidence from field enclosures and observations in the Northern Gulf of Mex1Co. J Exp Mar Biol Ecol 178:181-192

With KA, Crist TO (1995) Critical thresholds in species' responses to landscape structure. Ecology 76:2446-2459

Submitted: June 5, 1997; Accepted: June 8, 1997

Proofs recelved from a uthor(s): September 15, 1998 